Research Article

\title{
Prediction Model for Asphalt Pavement Temperature in High-Temperature Season in Beijing
}

\author{
Jing Chao ${ }^{1,2}$ and Zhang Jinxi ${ }^{1}{ }^{1}$ \\ ${ }^{1}$ Beijing Key Laboratory of Traffic Engineering, Beijing University of Technology, Beijing 100124, China \\ ${ }^{2}$ School of Civil Engineering and Mechanics, Yanshan University, Qinhuangdao 066004, China \\ Correspondence should be addressed to Zhang Jinxi; zhangjinxi@bjut.edu.cn
}

Received 3 April 2018; Accepted 19 June 2018; Published 26 July 2018

Academic Editor: Francesco Canestrari

Copyright (c) 2018 Jing Chao and Zhang Jinxi. This is an open access article distributed under the Creative Commons Attribution License, which permits unrestricted use, distribution, and reproduction in any medium, provided the original work is properly cited.

\begin{abstract}
Asphalt pavement temperatures greatly influence on the bearing capacity and performance, especially in high-temperature season. The variation rules of pavement temperatures under the high-temperature range affect the design and maintenance management of the asphalt pavement, as well as the accurate prediction for pavement temperatures. However, asphalt pavement temperature is greatly affected by various strongly correlated environmental factors and cannot be measured directly or predicted effectively. In this project, temperature sensors were embedded in the pavement of in-service road to collect temperature data by continuous record measurement, and regression model was conducted by the partial least squares method through comprehensive analysis on the pavement temperature data and synchronously environmental data from local weather station measured in July 2013 , July 2014, and July 2015. The quantitative relationships in high-temperature season between environmental factors and pavement temperature were determined, and a model was established to predict the temperature of asphalt pavement based on environmental data. The model was verified by the recorded data from July 1, 2016, to July 31, 2016, and the results indicated that the pavement temperature can be predicted accurately and reliably by the proposed model.
\end{abstract}

\section{Introduction}

The performance of asphalt pavement is highly sensitive to temperature [1]. In recent years, temperature in summer in China tends to be higher than ever due to global warming. In many provinces, it has been beyond $35^{\circ} \mathrm{C}$ in several days of July. The highest temperature in Beijing in summer generally appears in mid-July [2]. In other words, temperature in July achieves its maximum level. According to statistics released by China Meteorological Administration, not only does scorching weather rarely seen in summer of Beijing appear but precipitation has also been extremely low for the past few years. Such a phenomenon exerts a direct influence on asphalt pavement in service. To be specific, rutting can be formed in quantities as pavement temperature rises. Therefore, in-depth research on variation rules of asphalt pavement temperature in high-temperature seasons together with efficient prediction to pavement temperature is of great significance for design and maintenance management of the asphalt pavement.

Current research methods for the temperature field in asphalt pavement can be divided into two categories. One category refers to the theoretical analysis methods, in which the forecast models of pavement temperature field are mainly built based on the basic principles of heat transfer. In 2004, American MEPDG (mechanistic empirical pavement guide) continued to follow the basic principles of heat transfer, in which CMS (climatic materials structural) model utilized one-dimensional finite difference method to determine the temperature distribution of pavement. Based on the heat balance equation, Huber [3] established a deterministic formula for the maximum temperature of pavement. Christison and Anderson [4] put forward a model to predict the temperature of asphalt pavement based on onedimensional heat conduction equation. Qin and Hiller [5] proposed an improved one-dimensional heat conduction 
model to predict the temperature distribution of pavement. The main advantage of this kind of model is that the effects of air temperature on the temperature of rigid pavement slab with various depths can be obtained conveniently. According to different methods and theories, Thornes [6], Thornes and Shao [7, 8], Shao and Lister [9], T. Feng and S. Feng [10], and Elwakil et al. [11] proposed various factors affecting pavement temperature in different prediction models. Zuoren [12] and $\mathrm{Wu}$ [13] were both important pioneers of such theoretical analysis methods. Besides, in 2014, Gang [14] also used the finite difference method to analyze the distribution of asphalt pavement temperature field in Ganzhong area. The other category mainly involves the statistical analysis methods, which employ the statistical correlation method to analyze the intrinsic law between pavement temperature, external environment, and other measured data. The first large-scale application of such methods was in 1987, by the US, in the SHRP Program (Strategic Highway Research Program). Mohseni and Symons $[15,16]$ presented a statistical model for predicting the temperature of asphalt pavement, and their most valuable conclusion was that the maximum and the minimum temperatures in different depths of the pavement varied linearly with the changes of surface temperature and air temperature. Later on, Diefenderfer et al. [17] and Wang and Roesler [18] adopted the monthly mean temperature as a correction coefficient to extend the application scope of this model and thereby improved its prediction accuracy. Further, Marchetti et al. [19] proposed a model based on principal component analysis (PCA) and partial least squares (PLS) regression that used air temperature to predict temperature of road surface. In the past decade, many similar studies have also emerged in China, such as the reports from Cao et al. [20] and Kang et al. [21] in 2007, Bai et al. [22] in 2011, Xu et al. [23] in 2013, Dong et al. [24] in 2014, and Zeng et al. [25] in 2016.

By comparing the above two categories of research methods, it can be found that although the theoretical analysis methods have a strong universality, their prediction accuracy and application scope are greatly restricted due to the complexity of analysis models, the complicated process, the great number of input parameters, and the difficulty in obtaining accurate results. With the development of information acquisition technology and the maturity of sensor technology, more and more research tends to use the statistical analysis methods to explore the distribution of temperature field of road surface. Hence, the statistical analysis methods are the focus point of this paper. However, according to existing research results in this field, the statistical regularity of pavement temperature field has not been fully exploited because of the large variability of measured data and the complexity of influence factors. In 2013, Tan et al. [26] pointed out that a piece of floating cloud, a gust of wind, or a spatter of rain could all cause the fluctuations of road surface temperature. Luo et al. [27] reported that wind speed, daily maximum and minimum temperature, cloud cover, radiation, road surface reflectivity, sunshine time, and precipitation factors would all affect the mode of heat transfer between road and external environment. Sreedhar and Biligiri [28] suggested that pavement temperature was a function of various climatic and thermal properties, including wind speed, relative humidity, air temperature, and so on. Tan et al. [29] pointed out that most pavements were exposed to harsh natural environments so that their internal temperature was often affected by local climate and hydrological and meteorological factors (such as air temperature, air humidity, solar radiation, rainfall, and wind speed). These above results indicate that it is of great significance to study the influences of meteorological factors on pavement temperature.

For the in-service road, the density, heat capacity, and thermal conductivity of pavement materials are fixed, so the pavement temperature is mainly determined by environmental factors. On the other hand, many scholars have studied the pavement temperature field using the full-scale experiment pavement, but the working conditions of fullscale experiment pavement are still different from those of in-service pavement. In addition, some scholars also studied the prediction methods for surface temperature. In fact, the internal temperature of pavement is significantly different from that of road surface, which makes the former have a greater impact on pavement performance. Therefore, by embedding sensors in actual highways, this paper carried out regression analysis on the collected pavement temperature data and synchronously measured environmental data from local weather station, and established a prediction model with high accuracy for asphalt pavement temperature field in high-temperature season. It was verified that the proposed model could completely and comprehensively reveal the influences of environmental factors on the asphalt pavement temperature and the distribution regularity of temperature field in asphalt pavement in high-temperature season.

\section{Data Acquisition}

2.1. Acquisition of Pavement Temperature Data. The sensors were embedded in $\mathrm{K} 89+330$ of the outer ring road of the Six-Ring in the south of Beijing. Because of the heavy traffic volume and a considerable amount of heavy-load vehicles, the pavement breakage and rutting distress are very serious. Maintenance and repair work of the construction was carried out in September 2012. The maintenance plan was to cut the middle and top layers and then repave the middle and top layers to the same thickness as that before damages. Table 1 shows the pavement materials and structure of the road before and after pavement.

Temperature sensors were used as the monitoring equipment in this study, as shown in Figure 1. DTMCU80G20 remote monitoring unit was used for data collection and storage, as shown in Figure 2. All sensors were arranged right below the wheel-path area. Figure 3 shows the vertical section layout of the sensors. As can be seen, the sensors were embedded at the bottom of the top layer, the bottom of the bottom layer, and $5 \mathrm{~cm}$ below the base, respectively. $T_{5}$ denotes the pavement temperature at $5 \mathrm{~cm}$ below the surface (the bottom of the top layer), ${ }^{\circ} \mathrm{C} ; T_{19}$ denotes the pavement temperature at $19 \mathrm{~cm}$ below the surface (the bottom of the bottom layer), ${ }^{\circ} \mathrm{C}$; and $T_{24}$ denotes the pavement temperature at $24 \mathrm{~cm}$ below the surface $\left(5 \mathrm{~cm}\right.$ below the base), ${ }^{\circ} \mathrm{C}$. In 
TABLE 1: Pavement structure of the test road.

\begin{tabular}{lcccc}
\hline \multirow{2}{*}{ Structure } & \multicolumn{2}{c}{ Pavement structure before M\&R } & \multicolumn{2}{c}{ Pavement structure after M\&R } \\
& Pavement materials & Thickness $(\mathrm{cm})$ & Pavement materials & Thickness $(\mathrm{cm})$ \\
\hline Top layer & SMA-16 & 5 & SBS SMA-16 \\
Middle layer & AC-20I & 7 & SBS AC-25 \\
Bottom layer & AC-25I & 7 & No change & 7 \\
Base course & Cement-stabilized gravel & 30 & No change & - \\
\hline
\end{tabular}

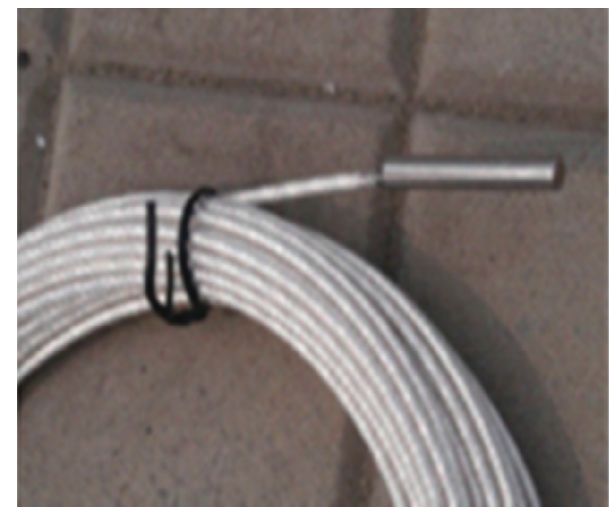

Figure 1: Temperature sensor.

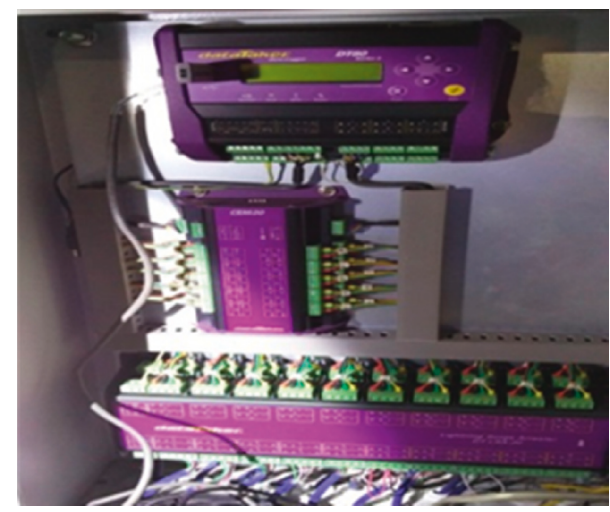

FIgURE 2: DTMCU80G-20 remote monitoring unit.

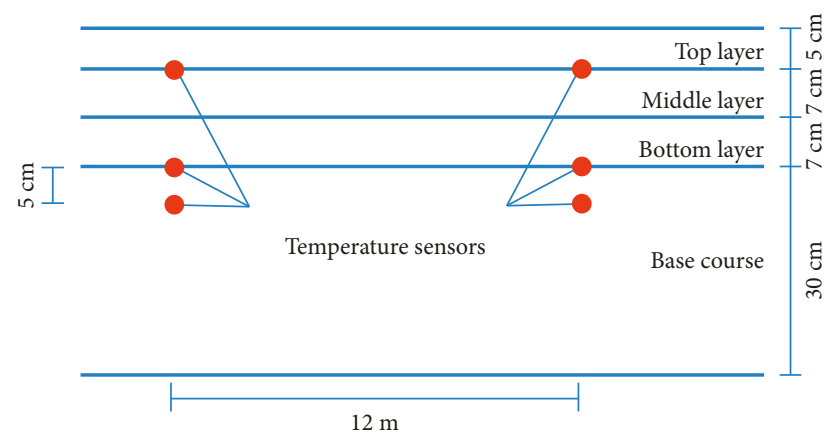

FIgURE 3: Vertical section layout of the sensors.

this study, two sets of temperature sensors were embedded along the traveling lane with $12 \mathrm{~m}$ apart to improve the accuracy of the monitoring data, and the temperature of

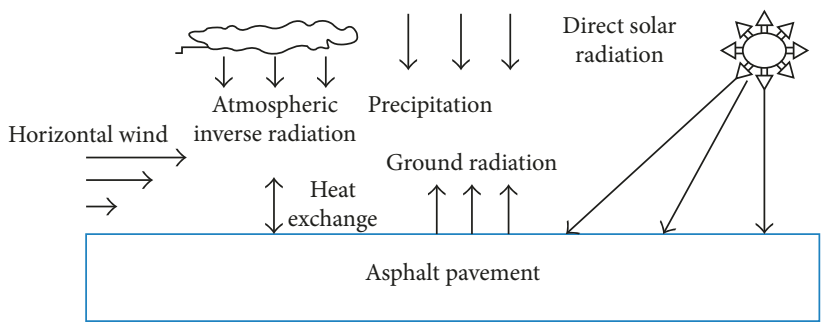

FIgURE 4: Temperature field diagram of interaction between asphalt pavement and environmental factors.

asphalt pavement in the test road was continuously monitored for 5 years since September 27, 2012.

2.2. Data Acquisition of Meteorological Factors. All data of meteorological factors (including temperature, $T$; cloud cover, $N$; humidity, $U$; wind speed, Ff; and precipitation, RRR) in this study were from the China National Weather Service 54,511 (Beijing) Observation Station. The station belongs to base station and is located in Beijing, $39.8^{\circ} \mathrm{N}$, $116.47^{\circ} \mathrm{E}$, with an altitude of $31.3 \mathrm{~m}$. For the meteorological data, $T_{\text {air }}$ is the air temperature $2 \mathrm{~m}$ above the ground, ${ }^{\circ} \mathrm{C}$; $N$ is the total cloud cover, \%; $U$ is the air relative humidity $2 \mathrm{~m}$ above the ground, \%; Ff is the average wind speed $10-12 \mathrm{~m}$ above the ground $10 \mathrm{~min}$ before the observation, $\mathrm{m} / \mathrm{s}$; and RRR is the precipitation, $\mathrm{mm}$.

\section{Analysis on Meteorological Factors and Pavement Temperature}

3.1. Effects of Meteorological Factors. Asphalt pavement is generally exposed to natural environment, and its internal temperature is greatly affected by environmental factors. A variety of complex heat exchange processes happen between the subgrade and pavement and the external environment, as shown in Figure 4. Figure 5 illustrates the influences of local meteorological factors (such as temperature, relative humidity, cloud cover, wind speed, and precipitation) on pavement temperature. Figure 5(a) shows the temperature and meteorological factors of the pavement at 2 o'clock on July 1 and July 5, 2013. As can be seen, the pavement temperature is different at the different depths, and the air temperature, relative air humidity, cloud cover, wind speed, and precipitation may affect the internal temperature of the pavement. What is more, the combination of different meteorological elements presents different weather characteristics and also has different effects on the internal temperature of the pavement. Even under the same air 


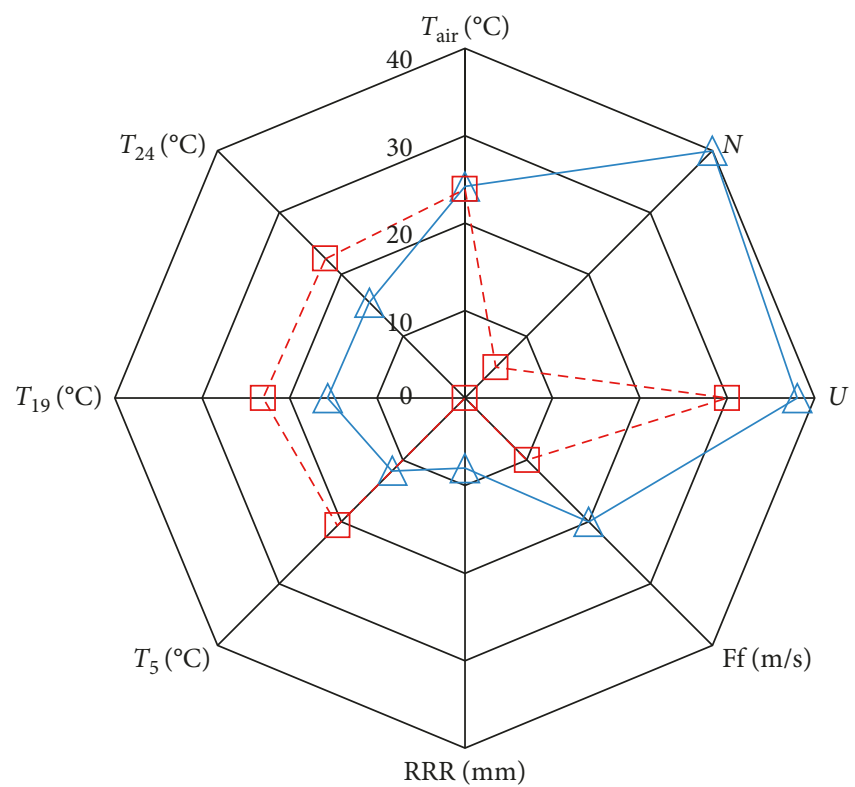

$\triangle 2013 / 7 / 1$

-曰- 2013/7/5

\begin{tabular}{ccccccccc}
\hline Date & $T_{\text {air }}\left({ }^{\circ} \mathrm{C}\right)$ & $N(\%)$ & $U(\%)$ & $\mathrm{Ff}(\mathrm{m} / \mathrm{s})$ & $\mathrm{RRR}(\mathrm{mm})$ & $T_{5}\left({ }^{\circ} \mathrm{C}\right)$ & $T_{19}\left({ }^{\circ} \mathrm{C}\right)$ & $T_{24}\left({ }^{\circ} \mathrm{C}\right)$ \\
\hline 1-Jul & 24.2 & 100 & 95 & 2 & 8 & 11.8 & 15.7 & 15.4 \\
5-Jul & 23.9 & 12 & 75 & 1 & 0 & 20.6 & 23.1 & 22.5 \\
\hline
\end{tabular}

(a)

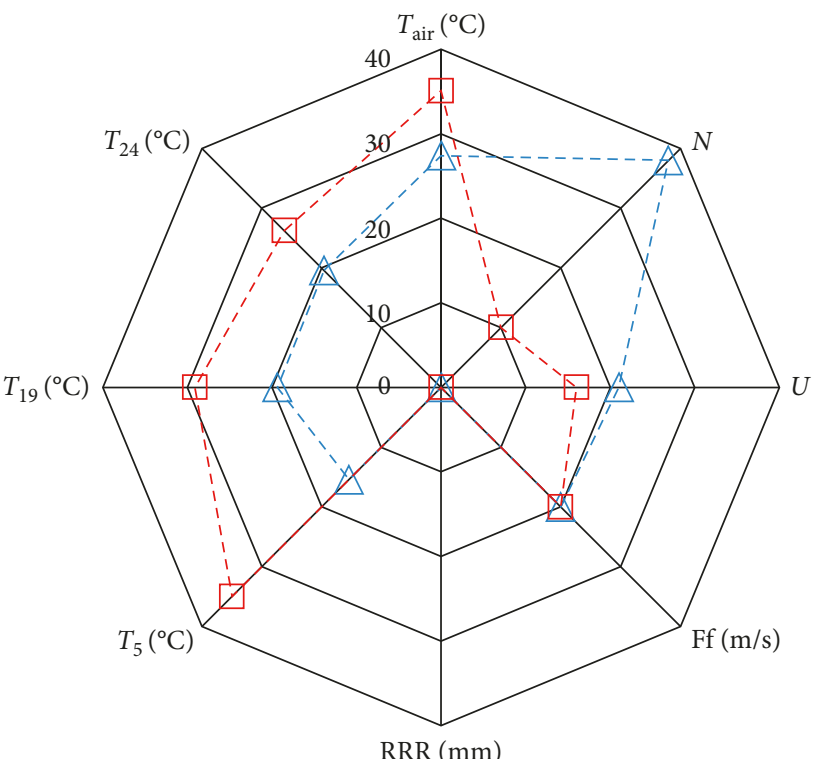

$-\Delta-5: 00$

一曰- 17:00

\begin{tabular}{lcccccccc}
\hline Time & $T_{\text {air }}\left({ }^{\circ} \mathrm{C}\right)$ & $N(\%)$ & $U(\%)$ & $\mathrm{Ff}(\mathrm{m} / \mathrm{s})$ & $\mathrm{RRR}(\mathrm{mm})$ & $T_{5}\left({ }^{\circ} \mathrm{C}\right)$ & $T_{19}\left({ }^{\circ} \mathrm{C}\right)$ & $T_{24}\left({ }^{\circ} \mathrm{C}\right)$ \\
\hline $5: 00$ & 27.4 & 95 & 52 & 2 & 0 & 15.4 & 19.4 & 19.6 \\
$17: 00$ & 35.1 & 25 & 41 & 2 & 0 & 35.0 & 29.1 & 26.2 \\
\hline
\end{tabular}

(b)

Figure 5: Influences of meteorological factors on pavement temperature. 
temperature, the internal temperature of pavement is also strikingly different due to the differences in other meteorological factors. Figure 5(b) shows the temperature and meteorological elements of the pavement at 5 o'clock and 17 o'clock on July 25, 2013. It can be observed that dramatic changes of the internal temperature of the pavement occur within 24 hours. The farther the measuring point is away from the road surface, the smaller the range of variation is. Under the combined action of some meteorological factors, the variation of $T_{5}$ can sometimes exceed that of $T_{\text {air }}$; the internal temperature of pavement is not always lower than $T_{\text {air }}$; and $T_{5}$ can be as high as $T_{\text {air. }}$. That is to say, $T_{5}$ can exceed $35^{\circ} \mathrm{C}$ in summer in Beijing. Hence, the problem of hightemperature stability is not only limited to road surface.

3.2. Variation of Pavement Temperature. Figure 6 shows the pavement temperature in July 2013. As can be seen, although the pavement temperature decreases with the increase of depth from road surface, the overall temperature of asphalt pavement in Beijing is very high in summer, and the maximum temperature can reach $35^{\circ} \mathrm{C}$ at the depth $5 \mathrm{~cm}$ from the road surface. In each day, the pavement temperature presents an approximately periodic fluctuation. The farther the measuring point is away from the road surface, the smaller the fluctuation is. However, because of the influences of meteorological factors, the daily temperature shows very huge differences. Figure 7 illustrates the temperature condition within an arbitrary continuous 72 -hour period. It can be seen that the internal pavement undergoes two stages every 24 hours, namely, the heating stage and the cooling stage. The heating stage is from 5:00 a.m. to 2:00 p.m., and the cooling stage is from 3:00 p.m. to 4:00 a.m. of the next day.

\subsection{Correlation Analysis of Meteorological Factors.} Meteorological factors refer to the physical quantities that are used to describe the physical state and phenomena related to weather conditions. Common meteorological factors mainly include air temperature, air humidity, cloud cover, wind speed, precipitation, etc. These factors can be directly obtained from observation, and they mutually influence and constraint one another as time varies. Hence, different combinations of meteorological elements can present different meteorological characteristics. In order to quantitatively analyze the correlations between various meteorological factors, the meteorological data in July 2013 were selected and correlation analysis was carried out in the heating stage and cooling stage, respectively. The results are shown in Tables 2 and 3 and Figure 8.

According to Tables 2 and 3 and Figure 8, the air temperature is negatively correlated with the cloud cover, air humidity, and precipitation and positively correlated with the wind speed; the cloud cover is positively correlated with the humidity and precipitation; the air humidity is negatively correlated with the wind speed and positively correlated with the precipitation; and there is a positive correlation between the wind speed and the precipitation. Overall, most of the meteorological elements are highly correlated. Therefore, if these variables were directly used to

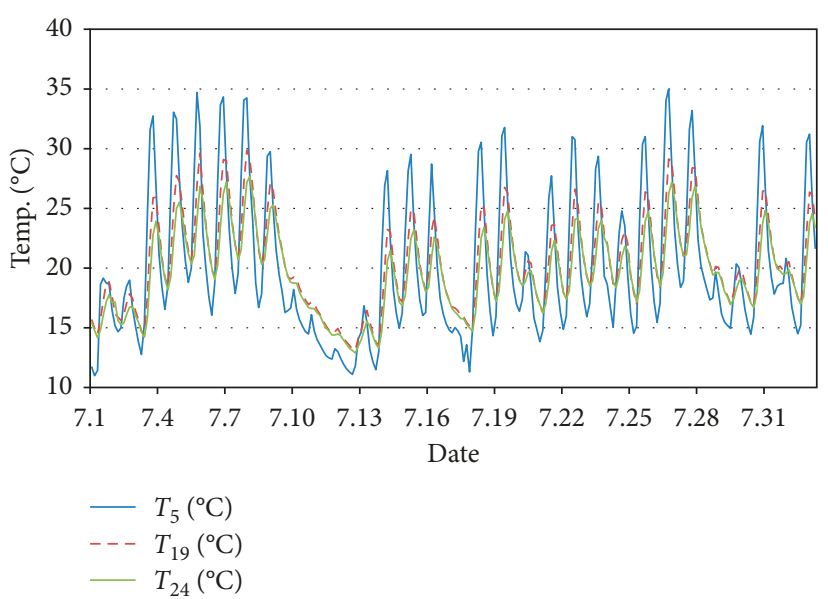

FIGURE 6: The pavement temperature in July.

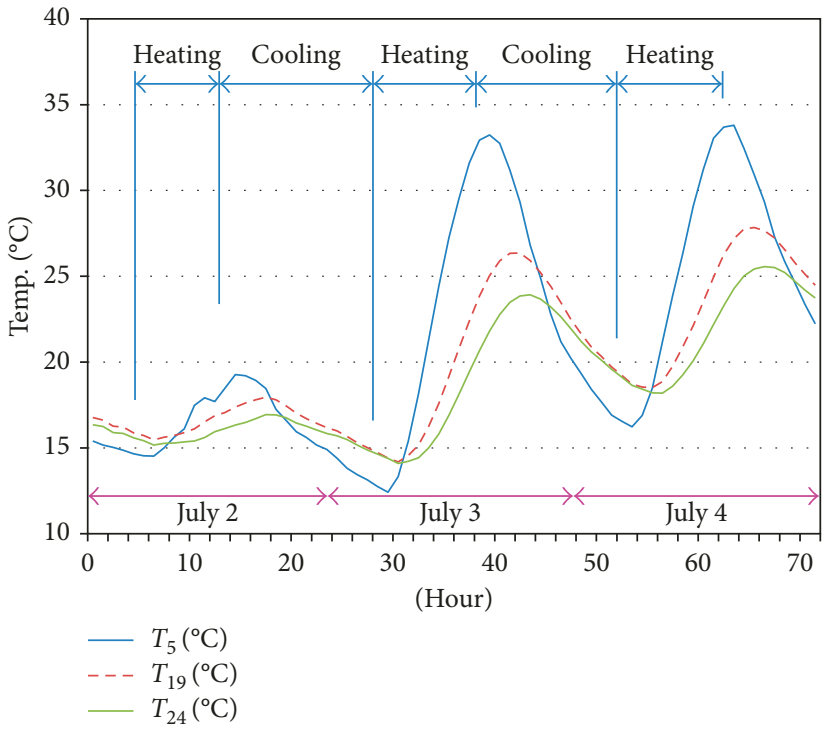

FIGURE 7: Variation of pavement temperature in any continuous 72-hour period.

TABLE 2: Correlation coefficients between meteorological factors in the heating stage.

\begin{tabular}{lccccc}
\hline & $T_{\text {air }}$ & $N$ & $U$ & Ff & RRR \\
\hline$T_{\text {air }}$ & 1.000 & $-0.321^{* * *}$ & $-0.894^{* * *}$ & $0.409^{* * *}$ & -0.147 \\
$N$ & $-0.321^{* * *}$ & 1.000 & $0.486^{* * *}$ & $-0.215^{* *}$ & 0.073 \\
$U$ & $-0.894^{* * *}$ & $0.486^{* * *}$ & 1.000 & $-0.515^{* * *}$ & $0.172^{*}$ \\
$\mathrm{Ff}$ & $0.409^{* * *}$ & $-0.215^{* *}$ & $-0.515^{* * *}$ & 1.000 & 0.001 \\
$\mathrm{RRR}$ & -0.147 & 0.073 & $0.172^{*}$ & 0.001 & 1.000 \\
\hline
\end{tabular}

Note. The symbols “***," «**," and “*” indicate that the correlation coefficients between two variables go through significance testing at the significant levels of $1 \%, 5 \%$, and $10 \%$, respectively. Obviously, Table 2 shows that there is a different degree for the correlations between explanatory variables at different significant levels.

conduct traditional least squares regression for establishing the prediction model of asphalt pavement temperature, there must be multiple collinearity in the regression model. As a result, the traditional multiple regression method fails to 
TABLE 3: Correlation coefficients between meteorological factors in the cooling stage.

\begin{tabular}{|c|c|c|c|c|c|}
\hline & $T_{\text {air }}$ & $N$ & $U$ & $\mathrm{Ff}$ & RRR \\
\hline$T_{\text {air }}$ & 1.000 & $-0.237^{* * *}$ & $-0.887^{* * *}$ & $0.484^{* * *}$ & $-0.272^{* * *}$ \\
\hline$N$ & $-0.237^{* * *}$ & 1.000 & $0.431^{* * *}$ & -0.130 & 0.112 \\
\hline$U$ & $-0.887^{* * *}$ & 0.431 & 1.000 & $-0.447^{* * *}$ & $0.225^{* *}$ \\
\hline $\mathrm{Ff}$ & $0.484^{* * *}$ & -0.130 & $-0.447^{* * *}$ & 1.000 & 0.039 \\
\hline RRR & $-0.272^{* * *}$ & 0.112 & $0.225^{* *}$ & 0.039 & 1.000 \\
\hline
\end{tabular}

Note. The symbols “***," “**," and “*” indicate that the correlation coefficients between two variables go through significance testing at the significant levels of $1 \%, 5 \%$, and $10 \%$, respectively. Obviously, Table 3 shows that there is a different degree for the correlations between explanatory variables at different significant levels.

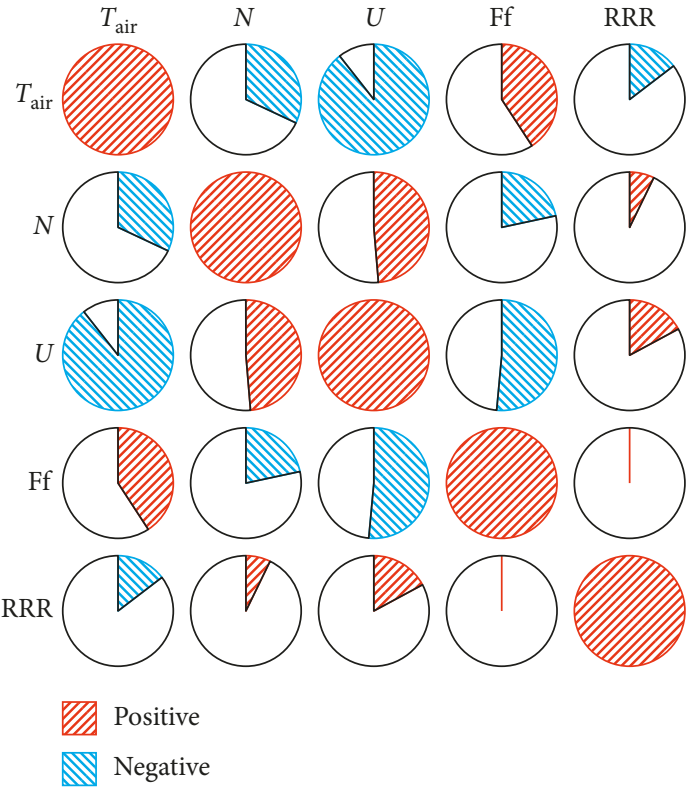

(a)

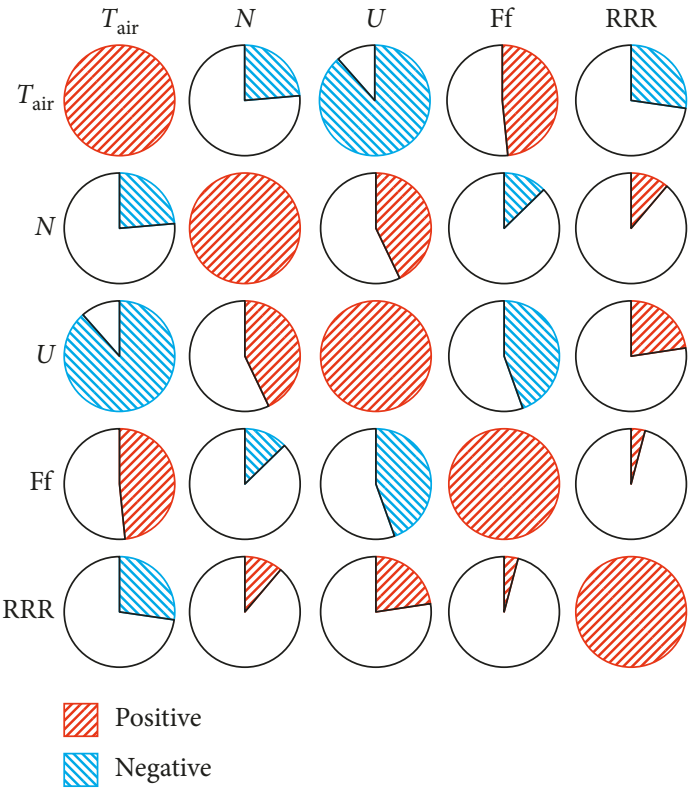

(b)

FIgURE 8: Correlation diagram between meteorological factors. (a) Heating stage and (b) cooling stage.

obtain the explanatory variables that influence the pavement temperature. In view of this, we need to use the partial least squares regression method to conduct regression analysis.

\section{Partial Least Squares Regression}

4.1. Introduction of the Partial Least Squares Regression Method. Partial least squares regression is a new method for multivariate statistical data analysis. In recent 20 years, it has developed rapidly in theories, methods, and applications. The importance of partial least squares regression in statistical applications can be summarized as follows:

(1) Partial least squares regression is a regressive modeling method by multiple dependent variables to multiple independent variables.

(2) Partial least squares regression can solve many problems that cannot be solved by ordinary multivariate regression, for example, multiple dependencies between arguments. In partial least squares regression, an effective technical approach is developed to decompose and filter the data information in the system, so that it can extract the most explanatory synthesis variables of dependent variables, identify the information and noise in the system, and thus overcome the adverse effects of multiple correlations between variables in the system modeling.

(3) Partial least squares regression can simplify the data structure during model construction, so the features of multidimensional data can be observed in the twodimensional planar graph, thus realizing the dimensionality reduction of the data $[30,31]$.

4.2. Modeling Process of the Partial Least Squares Regression Method. Suppose that there are $p$ interpreted variables recorded as $Y_{1}, Y_{2}, \cdots, Y_{p}$ and $m$ explanatory variables recorded as $X_{1}, X_{2}, \cdots, X_{m}$. Assume that $n$ variables from each set are selected for observation. Before conducting partial least squares regression, it is generally necessary to standardize the variables. That is, each variable value is subtracted by the mean value of all variables and then divided by the standard deviation. The processed independent variables and explanatory variables can be expressed by the following matrices: 


$$
\begin{aligned}
X_{0} & =\left(\begin{array}{cccc}
x_{11} & x_{12} & \cdots & x_{1 m} \\
x_{21} & x_{22} & \cdots & x_{2 m} \\
\vdots & \vdots & \ddots & \vdots \\
x_{n 1} & x_{n 2} & \cdots & x_{n m}
\end{array}\right), \\
Y_{0} & =\left(\begin{array}{cccc}
y_{11} & y_{12} & \cdots & y_{1 p} \\
y_{21} & y_{22} & \cdots & y_{2 p} \\
\vdots & \vdots & \ddots & \vdots \\
y_{n 1} & y_{n 2} & \cdots & y_{n p}
\end{array}\right) .
\end{aligned}
$$

This method can be implemented through the following several steps:

(1) The first pair of principal components of the independent variables and explanatory variables is extracted respectively, and the correlation of the principal components is maximized.

The first principal component extracted from $X=\left(X_{1}, X_{2}, \cdots, X_{m}\right)$ is $T_{1}$, and the first principal component extracted from $Y=\left(Y_{1}, Y_{2}, \cdots, Y_{p}\right)$ is $U_{1}$, that is:

$$
\begin{aligned}
& T_{1}=w_{1}^{\prime} X_{0}=w_{11} X_{1}+w_{12} X_{2}+\cdots+w_{1 m} X_{m}, \\
& U_{1}=v_{1}^{\prime} Y_{0}=v_{11} Y_{1}+v_{12} Y_{2}+\cdots+v_{1 p} Y_{p} .
\end{aligned}
$$

In order to enable $T_{1}$ and $U_{1}$ to extract the information of their own group as much as possible and maintain the highest relevant degree of $T_{1}$ and $U_{1}$, two groups of weight vectors $w_{1}$ and $v_{1}$ can be obtained by the main component regression and canonical correlation analysis. $w_{1}$ and $v_{1}$ can satisfy $w_{1}^{\prime} w_{1}=1, v_{1}^{\prime} v_{1}=1$, and the realization of $T_{1}$ is recorded as $t_{1}$.

(2) The regression models of $X_{1}, X_{2}, \ldots, X_{m}$ and $Y_{1}, Y_{2}, \ldots, Y_{p}$ to $T_{1}$ are established respectively as follows:

$$
\begin{aligned}
& X_{0}=t_{1} \alpha_{1}^{\prime}+E_{1}, \\
& Y_{0}=t_{1} \beta_{1}^{\prime}+F_{1},
\end{aligned}
$$

where $\alpha^{\prime}=\left(\alpha_{11}, \alpha_{12}, \ldots, \alpha_{1 m}\right), \beta^{\prime}=\left(\beta_{11}, \beta_{12}, \ldots, \beta_{1 p}\right)$ are the regression coefficient vectors of a plurality of dependent variables to an explanatory variable respectively, and $E_{1}$ and $F_{1}$ are the corresponding residual matrices. The parameters obtained according to ordinary least squares (OLS) are estimated to be $[29,30]$ :

$$
\begin{aligned}
\widehat{\alpha}_{1}^{\prime} & =\left(t_{1}^{\prime} t_{1}\right)^{-1} t_{1}^{\prime} X_{0}, \\
\widehat{\beta}_{1}^{\prime} & =\left(t_{1}^{\prime} t_{1}\right)^{-1} t_{1}^{\prime} Y_{0} .
\end{aligned}
$$

The residual matrices $E_{1}$ and $F_{1}$ are estimated as follows:

$$
\begin{aligned}
& \widehat{E}_{1}=X_{0}-t_{1} \widehat{\alpha}_{1}^{\prime}, \\
& \widehat{F}_{1}=Y_{0}-t_{1} \widehat{\beta}_{1}^{\prime} .
\end{aligned}
$$

Then, use $\widehat{E}_{1}$ and $\widehat{F}_{1}$ to substitute $X_{0}$ and $Y_{0}$ in the first step and extract the second pair of principal components $T_{2}$ and $U_{2}$. The corresponding weight vectors $w_{2}$ and $v_{2}$ can satisfy $w_{2}^{\prime} w_{2}=1, v_{2}^{\prime} v_{2}=1$, and the realization of $T_{2}$ is recorded as $t_{2}$. Next, the regression is carried out.
The above process shall be carried out constantly until $r$ pairs of primary components are obtained, of which $r=\min (n-1, m)$. At this moment, it can be obtained as follows:

$$
\begin{aligned}
& X_{0}=t_{1} \widehat{\alpha}_{1}^{\prime}+t_{2} \widehat{\alpha}_{2}^{\prime}+\cdots+t_{r} \widehat{\alpha}_{r}^{\prime}+E_{r}, \\
& Y_{0}=t_{1} \widehat{\beta}_{1}^{\prime}+t_{2} \widehat{\beta}_{2}^{\prime}+\cdots+t_{r} \widehat{\beta}_{r}^{\prime}+F_{r} .
\end{aligned}
$$

Introduce $t_{k}=w_{k}^{\prime} X_{0}, \quad k=1,2, \ldots, r$, and the regression model of certain normalized dependent variable $Y_{j}^{*}$ can be obtained as follows:

$$
Y_{j}^{*}=a_{j 1} X_{1}^{*}+a_{j 2} X_{2}^{*}+\cdots+a_{j m} X_{m}^{*}, \quad j=1,2, \ldots, p,
$$

where the symbol "**," which indicates the variable processed by centralization, can be introduced to obtain the regression model of primitive variables.

(3) Determine the number of the extracted main components. In general, not every single one of the primary components can be extracted. A certain method is often adopted to determine the number of the extracted primary components. The commonly used ones include "leave-one-out cross validation," "group cross validation," "split-sample cross validation," and "random sample cross validation." Among them, "leave-one-out cross validation" is more commonly used. In this method, one observation (e.g., the no. $i$ observation) is left out each time, and the remaining $n-1$ observations are used to complete the principal component extraction, thereby obtaining an estimation model; then, the estimation model is employed to estimate the no. $i$ observation. When $k$ principal components are used, the predicted value of $y_{i j}$ is $\hat{y}_{j(i)}(k)$, and the predicted residual of the no. $j$ dependent variable after leaving out the no. $i$ observation is $y_{i j}-\hat{y}_{j(i)}(k)$. Therefore, the residual squares of all observations and all dependent variables are predicted to be as follows:

$$
\operatorname{PRESS}(k)=\sum_{j=1}^{p} \sum_{i=1}^{n}\left(y_{i j}-\hat{y}_{j(i)}(k)\right)^{2} .
$$

The determined number of principal components is selected to minimize the result of $l=\min _{1 \leq k \leq r}(\operatorname{PRESS}(k))$.

\section{Prediction Model of Pavement Temperature}

5.1. Data Preparation. In order to quantitatively study the influences of air temperature, cloud cover, air humidity, wind speed, precipitation, and other environmental factors on asphalt pavement temperature and to predict the temperature situation in pavement in hot weathers, in this paper, internal temperature data and meteorological element data of the pavement measured in July 2013, July 2014, and July 2015 were selected. The data were collected at $2,5,8,11,14$, 17,20 , and 23 o'clock in each day, that is, eight groups of data each day. Thus, a total of 744 samples were obtained. These 
TABLE 4: Correlation coefficients of all variables.

\begin{tabular}{lcccccccc}
\hline & $T_{\text {air }}$ & $N$ & $U$ & Ff & RRR & $T_{5}$ & $T_{19}$ \\
\hline$T_{\text {air }}$ & 1 & -0.237 & -0.887 & 0.484 & -0.272 & 0.615 & 0.468 \\
$N$ & -0.237 & 1 & 0.431 & -0.130 & 0.112 & 0.053 & 0.068 \\
$U$ & -0.887 & 0.431 & 1 & -0.447 & 0.225 & -0.509 & -0.393 \\
Ff & 0.484 & -0.130 & -0.447 & 1 & 0.039 & 0.329 & 0.204 & -0.325 \\
RRR & -0.272 & 0.112 & 0.225 & 0.039 & 1 & -0.163 & -0.179 & -0.149 \\
$T_{5}$ & 0.615 & 0.053 & -0.509 & 0.329 & -0.163 & 1 & 0.913 \\
$T_{19}$ & 0.468 & 0.068 & -0.393 & 0.204 & -0.179 & 0.913 & 1 \\
$T_{24}$ & 0.380 & 0.066 & -0.325 & 0.149 & -0.149 & 0.083 & 0.985 \\
\hline
\end{tabular}

samples included 248 samples in the heating stage and 372 samples in the cooling stage, upon which the prediction model for pavement temperature can be established. A detailed description of the cooling stage is as follows.

$T_{\text {air }}, N, U, F f$, and RRR represent the variables of air temperature, cloud cover, air humidity, wind speed, and precipitation, respectively; $T_{5}, T_{19}$, and $T_{24}$ represent the temperature $\left({ }^{\circ} \mathrm{C}\right)$ at the depth of $5 \mathrm{~cm}, 19 \mathrm{~cm}$, and $24 \mathrm{~cm}$ from road surface, respectively. The observed data matrix of the independent variables is recorded as $A=\left(a_{i j}\right)_{248 \times 5}$ and that of the dependent variables is recorded as $B=\left(b_{i j}\right)_{248 \times 3}$. Finally, various observed values $a_{i j} b_{i j}$ are converted into normalized values.

5.2. Correlation Matrix. The correlation coefficient matrix of all variables is shown in Table 4.

As can be seen, not only the independent variables are strongly correlated with each other but also the dependent variables are closely correlated with each other. These results again confirm that it is necessary to choose partial least squares regression for establishing the model.

5.3. Determination of the Number of Principal Components. The number of principal components is determined by means of leave-one-out cross validation. Table 5 provides the deviation percentage caused by partial least squares factors. As can be seen, the second principal component can explain that the deviation of model effects is $18.41 \%$ and that the variance of dependent variables is only $4.84 \%$. Obviously, the explanation of the second principal component to dependent variables is rather weak. Hence, the number of the extracted main components is 2 .

5.4. Determination of Regression Model. The regression relationships between normalized index variables and those between primitive variables obtained by SAS/STAT software are shown in Tables 6 and 7, respectively.

From Table 7, the prediction models of temperature at different depths in pavement during the cooling stage can be expressed as follows:

$$
\begin{gathered}
T_{5}=4.48+0.63 T_{\text {air }}+4.93 \mathrm{~N}-0.08 \mathrm{U}+0.52 \mathrm{Ff}-0.15 \mathrm{RRR}, \\
T_{19}=12.25+0.36 T_{\text {air }}+3.17 \mathrm{~N}-0.04 U+0.24 \mathrm{Ff}-0.08 \mathrm{RRR}, \\
T_{24}=13.96+0.26 T_{\text {air }}+2.39 \mathrm{~N}-0.03 \mathrm{U}+0.16 \mathrm{Ff}-0.06 \mathrm{RRR} .
\end{gathered}
$$

TABle 5: Percent variation caused by partial least squares factors.

\begin{tabular}{lcccc}
\hline \multirow{2}{*}{$\begin{array}{l}\text { Number of extracted } \\
\text { factors }\end{array}$} & \multicolumn{2}{c}{ Model effects } & \multicolumn{2}{c}{$\begin{array}{c}\text { Dependent } \\
\text { variables }\end{array}$} \\
& Current & Total & Current & Total \\
\hline 1 & 47.30 & 47.30 & 23.20 & 23.20 \\
2 & 18.41 & 65.71 & 4.84 & 28.04 \\
\hline
\end{tabular}

TABLE 6: Regression relationships between normalized index variables.

\begin{tabular}{lccc}
\hline & $T_{5}$ & $T_{19}$ & $T_{24}$ \\
\hline$T_{\text {air }}$ & 0.37 & 0.30 & 0.25 \\
$N$ & 0.28 & 0.25 & 0.22 \\
$U$ & -0.24 & -0.19 & -0.15 \\
Ff & 0.08 & 0.05 & 0.04 \\
RRR & -0.10 & -0.08 & -0.06 \\
\hline
\end{tabular}

TABLE 7: Regression relationships between primitive variables.

\begin{tabular}{lccc}
\hline & $T_{5}$ & $T_{19}$ & $T_{24}$ \\
\hline Intercept & 4.48 & 12.25 & 13.96 \\
$T_{\text {air }}$ & 0.63 & 0.36 & 0.26 \\
$N$ & 4.93 & 3.17 & 2.39 \\
$U$ & -0.08 & -0.04 & -0.03 \\
Ff & 0.52 & 0.24 & 0.16 \\
RRR & -0.15 & -0.08 & -0.06 \\
\hline
\end{tabular}

Similarly, the prediction models of temperature at different depths in pavement during the heating stage are as follows:

$$
\begin{aligned}
T_{5} & =-26.21+1.47 T_{\text {air }}-1.70 \mathrm{~N}+0.07 \mathrm{U}+0.26 \mathrm{Ff}+0.04 \mathrm{RRR}, \\
T_{19} & =-0.55+0.58 T_{\text {air }}-0.42 \mathrm{~N}+0.06 \mathrm{U}+0.02 \mathrm{Ff}+0.03 \mathrm{RRR}, \\
T_{24} & =5.32+0.36 T_{\text {air }}-0.87 \mathrm{~N}+0.05 \mathrm{U}+0.10 \mathrm{Ff}+0.03 \mathrm{RRR} .
\end{aligned}
$$

\subsection{Model Analysis and Test}

5.5.1. Model Analysis. Figure 9 shows the regression coefficients drawn by the normalized index variables. As can be seen from Figure 9 (a), $T_{\text {air }}, N$, and $U$ play an important role in interpreting the three regression equations during the cooling stage. That is, air temperature, $T_{\text {air }}$; cloud cover, $N$; and air humidity, $U$, have greater influences on the 


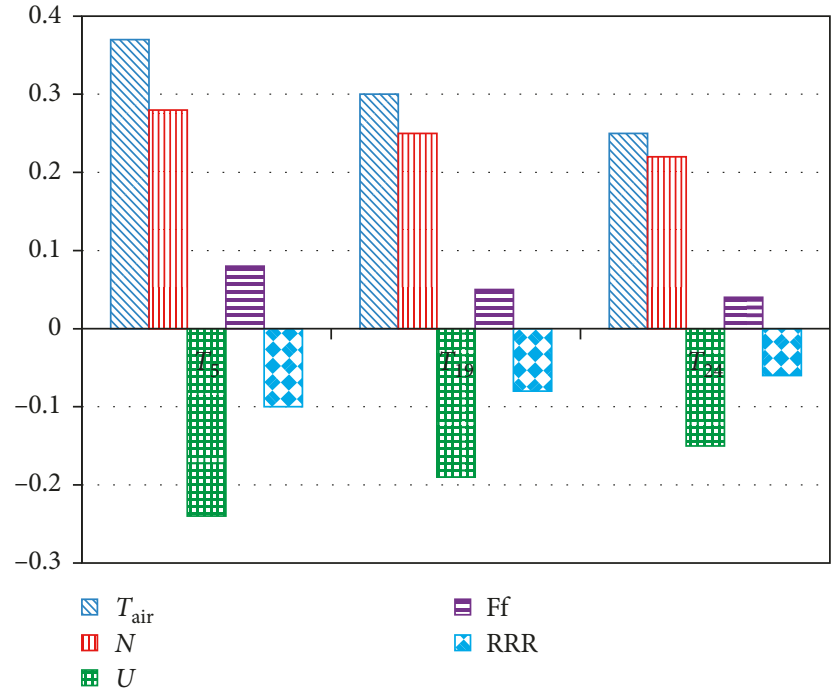

(a)

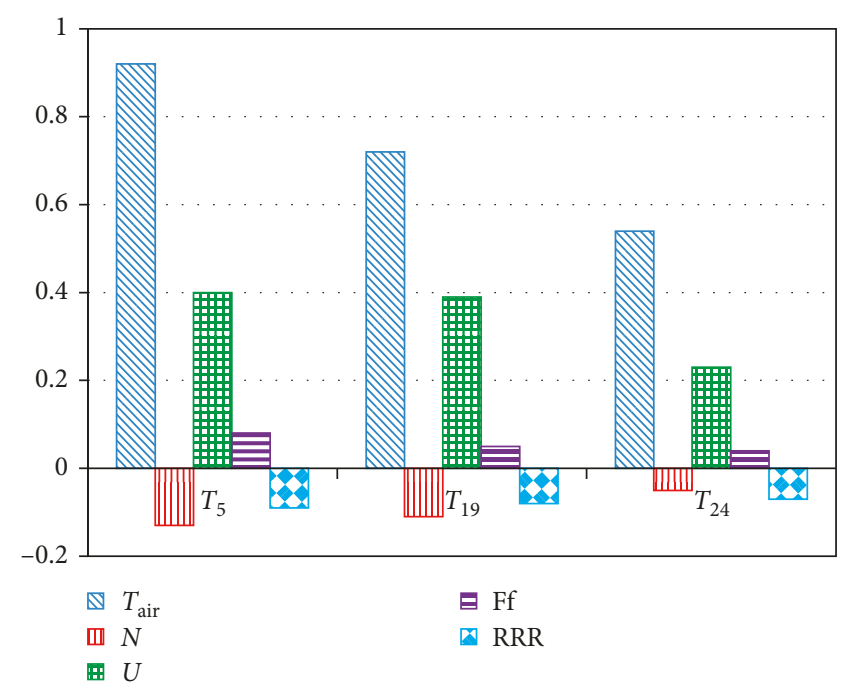

(b)

Figure 9: Regression coefficient histogram. (a) Cooling stage and (b) heating stage.

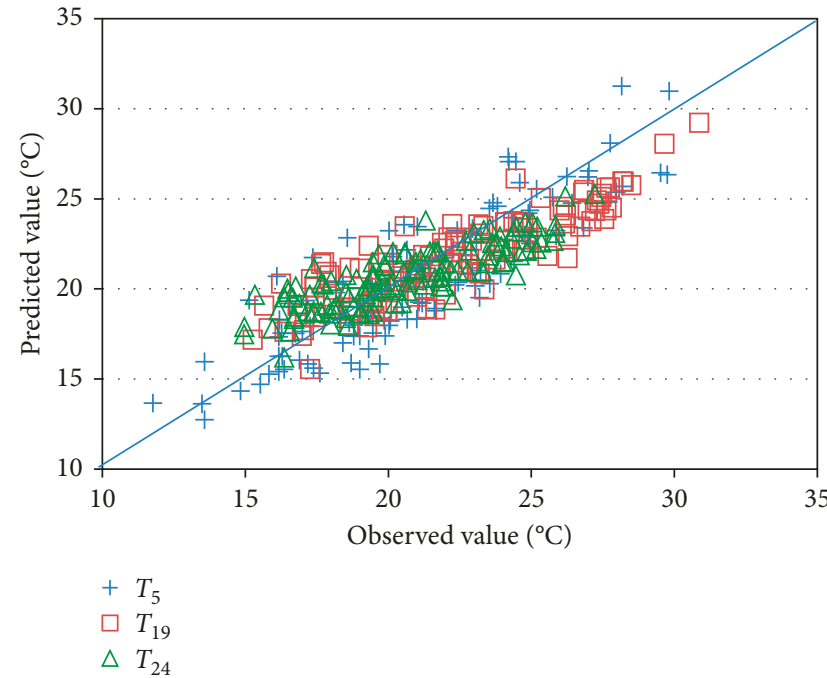

(a)

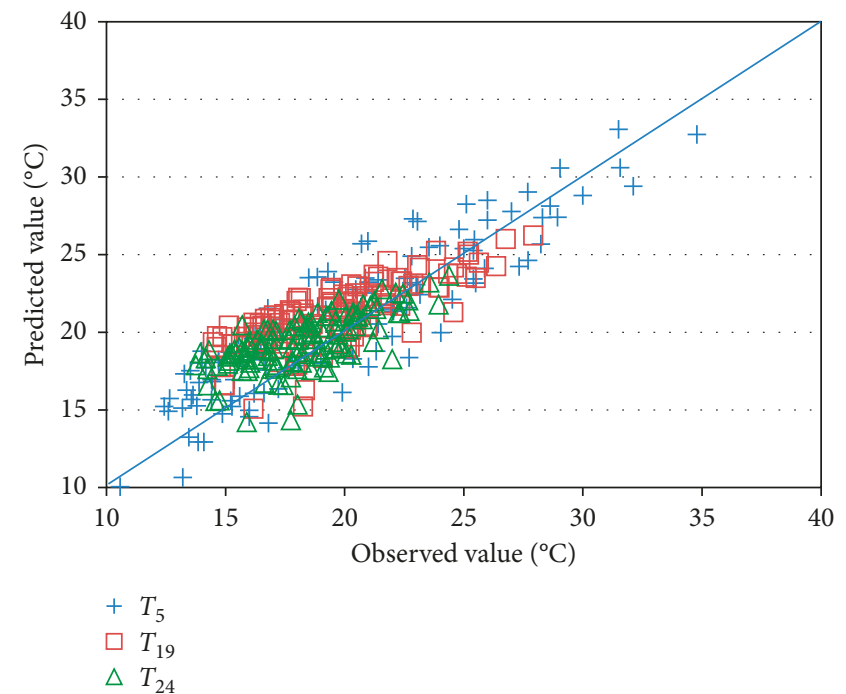

(b)

Figure 10: Predicted and observed pavement temperature. (a) Cooling stage and (b) heating stage.

temperature in pavement during the cooling stage, while the effects of wind speed, Ff, and precipitation, RRR, on the temperature in the pavement are relatively weaker. What is more, the influences of all these five variables decrease with the increase of the depth from road surface. Figure 9(b) indicates that $T_{\text {air }}$ and $U$ play an important role in interpreting the three regression equations during the heating stage, while the effects of $N, \mathrm{Ff}$, and RRR are relatively weaker. Meanwhile, the effect of $T_{\text {air }}$ on the temperature in pavement decreases with the increase in the depth from road surface. To sum up, the effect of cloud cover $N$ in the cooling stage is greater than that in the heating stage, and the air temperature $T_{\text {air }}$ plays a more important role in the heating stage than in the cooling stage.
5.5.2. Model Test. Since meteorological data are published in real time, they can be used to estimate the temperature in pavement at any time. In this study, the prediction model was applied to predict the temperature in pavement in July 2016 (at 2, 5, 8, 11, 14, 17, 20, and 23 o'clock on a daily basis, 31 days in total). All variables were used to predict $T_{5}, T_{19}$, and $T_{24}$, and the results are shown in Figure 10. As observed, the prediction results match well with the observed pavement temperatures, thus validating the robustness of the model.

\section{Conclusions}

In summary, temperature sensors were embedded in the inservice pavement to collect temperature data, and 
a regression model was established by the partial least squares method through comprehensive analysis on the pavement temperature data and synchronously measured environmental data. Furthermore, the quantitative relationships between environmental factors and pavement temperature were determined, and a statistical model was obtained to predict the asphalt pavement temperature with the environmental data. Some conclusions can be drawn as follows:

(1) Environmental factors that affect pavement temperature include air temperature, relative humidity of air, cloud cover, wind speed, and precipitation. Different factors present different meteorological characteristics and have different influences on pavement temperature.

(2) The maximum temperature at the depth $(5 \mathrm{~cm})$ from road surface in Beijing can reach $35^{\circ} \mathrm{C}$ in hightemperature season. Since this position is also the spot with maximum shear stress, the hightemperature stability is not only limited to road surface.

(3) The correlations among these factors (air temperature, relative humidity, cloud cover, wind speed, and precipitation) are quantified and linked in these models. The strong correlations of these factors were observed.

(4) Air temperature and relative humidity of air have greater influences while cloud cover, wind speed, and precipitation have weaker influences on pavement temperature during the heating stage. The influence of air temperature on pavement temperature weakened with the depth increase of testing positions from the road surface. The effect of cloud cover in the cooling stage is greater than that in the heating stage, and air temperature plays a more important role in the heating stage than in the cooling stage.

(5) The prediction model is verified based on the environmental data in July 2016, and the regression model was developed with a desirable stability and reliability, as well as a high accurate prediction.

\section{Data Availability}

Due to the particularity of the project, the data used to support the findings of this study are unavailable now.

\section{Conflicts of Interest}

The authors declare that there are no conflicts of interest regarding the publication of this paper.

\section{Acknowledgments}

The research and publication of the article was funded by the National Natural Science Foundation of China (Grant no. 51478021), 2015 Key Project of Beijing Natural Science Foundation or Key Technology Project of Beijing Municipal Commission of Education (Grant no. KZ201510005002), and
Central Government Guided Local Science and Technology Development Project (Project no. Z161100004516014).

\section{References}

[1] L. Sun and J. Qin, "Prediction model on temperature field in asphalt pavement," Journal of Tongji University, vol. 34, no. 4, pp. 480-483, 2006.

[2] D. Zhang, C. Deng, and S. Li, "Analysis of climatic characteristics in midsummer in Beijing," Meteorological Science and Technology, vol. 36, no. 6, pp. 768-771, 2008.

[3] G. A. Huber, Weather Database for the SUPERPAVE (Trademark) Mix Design System, Strategic Highway Research Program, SHRP-A-648A, National Research Council, Washington, DC, USA, 1994.

[4] J. T. Christison and K. O. Anderson, "The response of asphalt pavements to low temperature climatic environments," in Proceedings of Third International Conference on the Structural Design of Asphalt Pavements, pp. 41-52, Grosvenor House, Park Lane, London, Uk, 1972.

[5] Y. Qin and J. E. Hiller, "Modeling temperature distribution in rigid pavement slabs: impact of air temperature," Construction and Building Materials, vol. 25, no. 9, pp. 3753-3761, 2011.

[6] J. E. Thornes, The prediction of ice formation on motorways in Britain, Ph.D. thesis, University of London, London, UK, 1984.

[7] J. E. Thornes and J. Shao, "A comparison of UK road ice prediction models," Meteorological Magazine, vol. 120, no. 1424, pp. 51-57, 1991.

[8] J. E. Thornes and J. Shao, "Spectral analysis and sensitivity tests for a numerical road surface temperature prediction model," Meteorological Magazine, vol. 120, no. 1428, pp. 117-124, 1991.

[9] J. Shao and P. J. Lister, "An automated nowcasting model of road surface temperature and state for winter road maintenance," Journal of Applied Meteorology, vol. 35, no. 8, pp. 1352-1361, 1996.

[10] T. Feng and S. Feng, "A numerical model for predicting road surface temperature in the highway," Procedia Engineering, vol. 37, pp. 137-142, 2012.

[11] E. Elwakil, A. Eweda, and T. Zayed, "Modeling the effect of various factors on the condition of pavement marking," Structure and Infrastructure Engineering, vol. 10, no. 1, pp. 93-105, 2014.

[12] Y. Zuoren, "Analysis of the temperature field in layered pavement system," Journal of Tongji University, vol. 3, pp. 76-85, 1984.

[13] G. Wu and T. Ling, "The analysis of developing mechanism of thermal crack of the semi-rigid roadbase," China Journal of Highway and Transport, vol. 11, no. 1, pp. 21-28, 1998.

[14] X. Gang, Road Temperature Distribution of Asphalt Pavement Research on Central Jiangxi Province, Chongqing Jiaotong University, Chongqing, China, 2014.

[15] A. Mohseni and M. Symons, "Effect of improved LTPP AC pavement temperature models on superpave performance grades," in Proceedings of 77th Annual TRB Conference, Washington, DC, USA, 1998.

[16] A. Mohseni and M. Symons, "Improved ad pavement temperature models from LTPP seasonal data," in Proceedings of 77th Annual Transportation Research Board (TRB) Conference, Washington, DC, USA, 1998.

[17] B. K. Diefenderfer, I. L. Al-Qadi, S. D. Reubush et al., "Development and validation of a model to predict pavement 
temperature profile," in Proceedings of TRB 2003 Annual Meeting, Washington, DC, USA, 2003.

[18] D. Wang and J. R. Roesler, "One-dimensional rigid pavement temperature prediction using Laplace transformation," Journal of Transportation Engineering, vol. 138, no. 9, pp. 1171-1177, 2012.

[19] M. Marchetti, A. Khalifa, and M. Bues, "Methodology to forecast road surface temperature with principal components analysis and partial least-square regression: application to an urban configuration," Advances in Meteorology, vol. 2015, Article ID 562621, 10 pages, 2015.

[20] L. Cao, Z. Dong, and L. Sun, "Research on permanent deformation of asphalt pavement considering pavement temperature distribution," Journal of Tongji University, vol. 35, no. 12, pp. 1617-1621, 2007.

[21] H.-g. Kang, Y.-x. Zheng, Y.-c. Cai et al., "Regression analysis of actual measurement of temperature field distribution rules of asphalt pavement," China Journal of Highway and Transport, vol. 20, no. 6, pp. 13-18, 2007.

[22] Q. Bai, Z. Qian, H. Li et al., "Asphalt pavement temperature field model based on statistic regression method," Journal of Highway and Transportation Research and Development, vol. 28, no. 11, pp. 27-31, 2011.

[23] H.-n. Xu, R. Zhang, Y.-q. Tan et al., “Temperature distribution of pavement in seasonally frozen regions in winter," China Journal of Highway and Transport, vol. 26, no. 2, pp. 7-14, 2013.

[24] Z.-j. Dong, S.-l. Li, J.-y. Wen et al., "Real-time temperature field measurement of asphalt pavement based on fiber bragg grating measuring technology," Journal of Traffic and Transportation Engineering, vol. 14, no. 2, pp. 1-6, 2014.

[25] F. Zeng and Y. Jiang, "Research on the stochastic model for pavement temperature prediction," Highway, vol. 10, pp. 1-8, 2016.

[26] Z. Tan, Z. Ma, and X. Zou, "Pavement temperature estimation model based on field temperature data," Journal of Tongji University, vol. 41, no. 5, pp. 700-704, 2013.

[27] T. Luo, Q.-d. Tao, and J. Wu, "Analysis of temperature field characteristics of asphalt concrete pavement structure based on measured data," Journal of Highway and Transportation Research and Development, vol. 32, no. 10, pp. 30-36, 2015.

[28] S. Sreedhar and K. P. Biligiri, "Development of pavement temperature predictive models using thermophysical properties to assess urban climates in the built environment," Sustainable Cities and Society, vol. 22, pp. 78-85, 2016.

[29] Z. Tan, Q. Li, and B. Xiao, "The effect of meteorological factors on asphalt pavement internal temperature and quantitative analysis," Highway Engineering, vol. 41, no. 4, pp. 180-183, 2016.

[30] H.-w. Wang, Z.-b. Wu, and J. Meng, Partial Least-Squares Regression-Linear and Nonlinear Methods, National Defend Industry Press, Beijing, China, 2006.

[31] M. A. Mingde, M. A. Xuejuan, Y. Xie et al., "Analysis the relationship between ecological footprint ( $\mathrm{EF}$ ) of ningxia and influencing factors: partial least-squares regression (PLS)," Acta Ecologica Sinica, vol. 34, no. 3, pp. 682-689, 2014. 


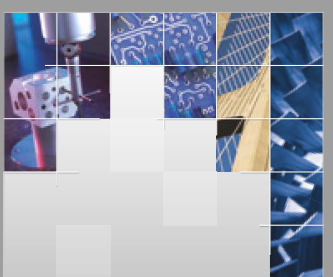

\section{Enfincering}
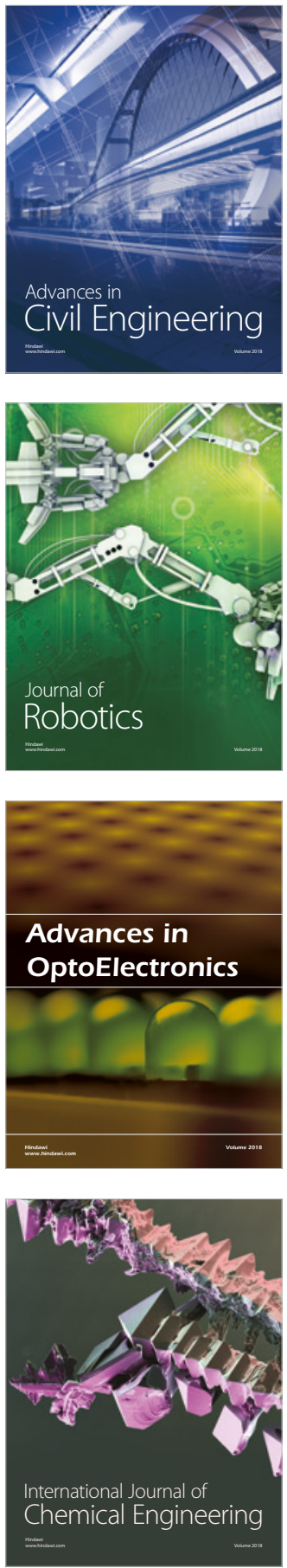

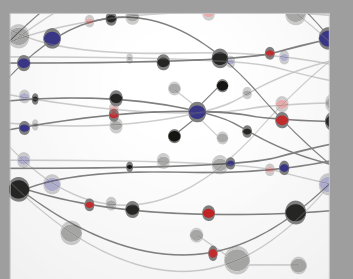

\section{Rotating \\ Machinery}

The Scientific World Journal

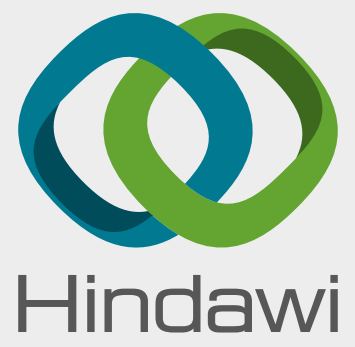

Submit your manuscripts at

www.hindawi.com
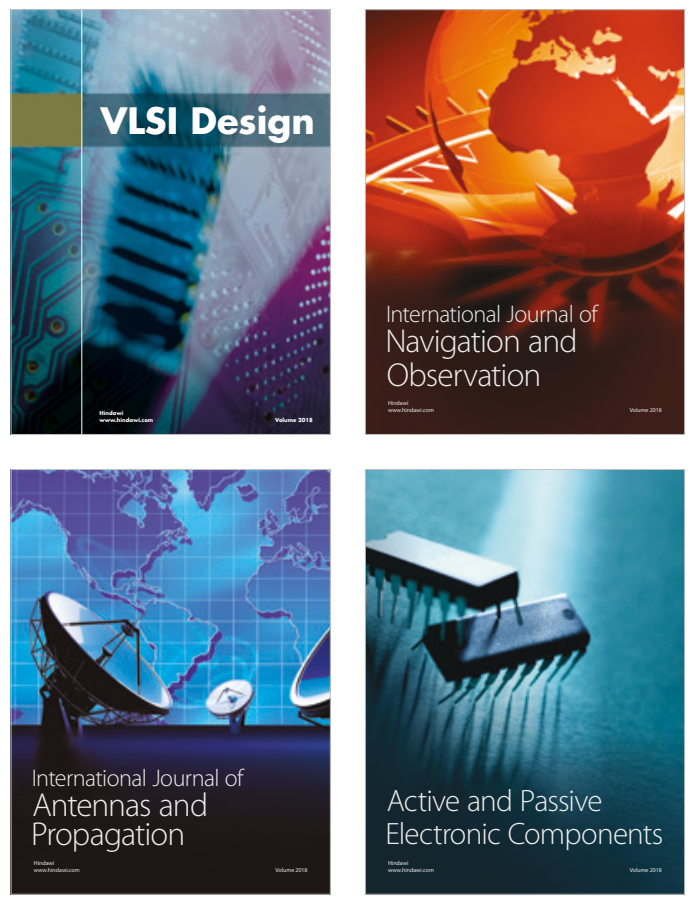
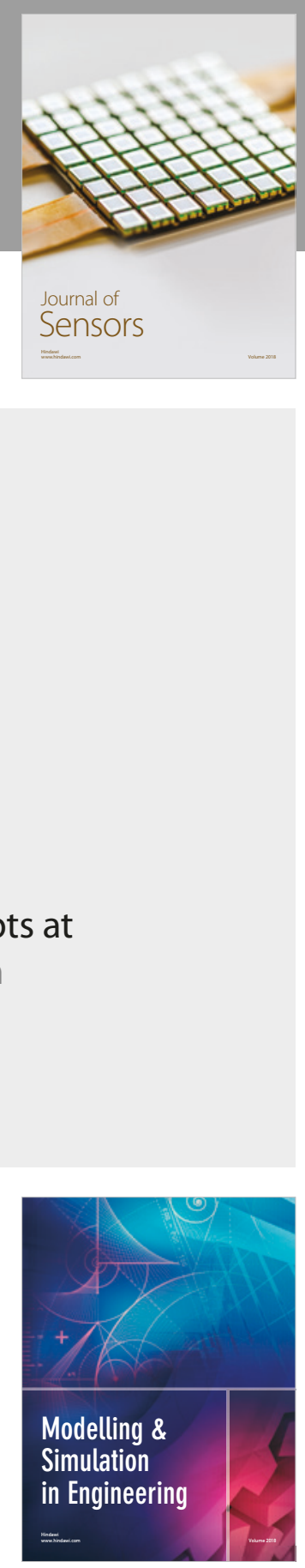

\section{Advances \\ Multimedia}
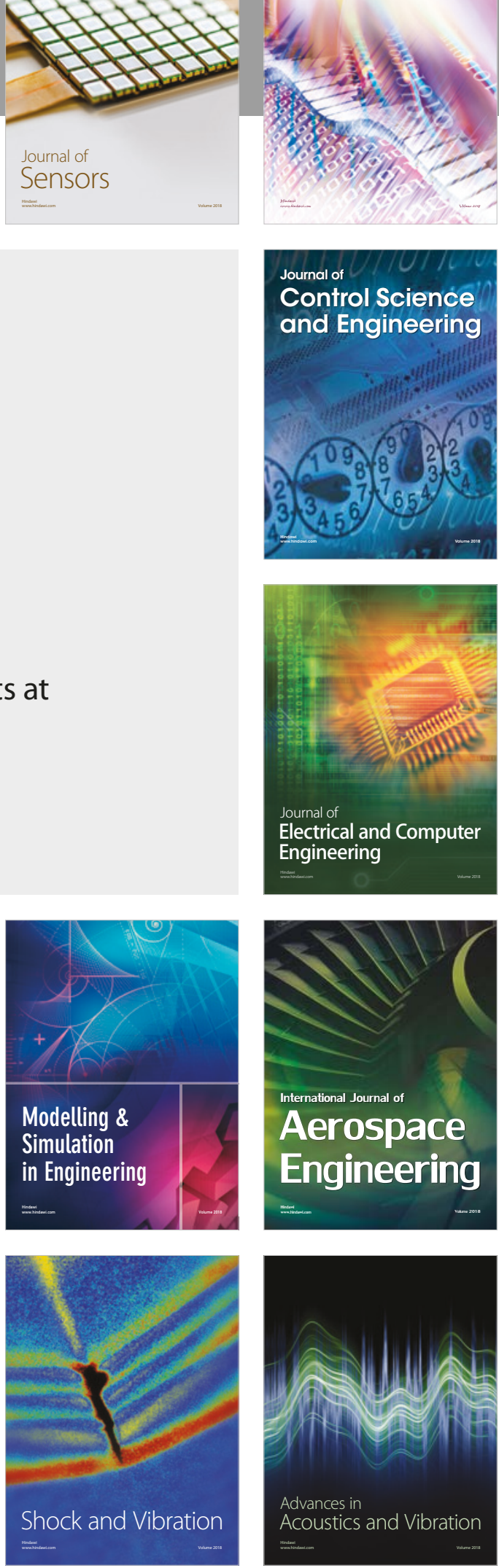